\title{
Analisis Pengelolaan Persampahan di Kota Pangkajene Kabupaten Pangkep
}

\author{
Wona Grace Boro
}

\author{
Dosen Program Studi Teknik Sipil, Universitas Kristen Indonesia Paulus, Makassar, Indonesia \\ gracewona@gmail.com
}

\begin{abstract}
ABSTRAK
Meningkatnya jumlah penduduk sangat mempengaruhi jumlah timbulan sampah. Banyaknya jumlah sampah tidak didukung dengan jumlah sarana dan prasarana pengelolaan sampah sehingga mengakibatkan permasalahan dalam pengelolaan sampah, seperti pengangkutan sampai pembuangan akhir sampah yang tidak terakomodir dengan baik sehingga menimbulkan penyakit, lingkungan kotor, mengurangi kapasitas tampung sungai dan sebagainya. Penelitian ini dilakukan untuk mengetahui cara pengelolaan sampah yang ada di kota Pangkajene dan menentukan kebutuhan infrastruktur untuk kegiatan operasional persampahan. Penelitian ini adalah penelitian deskriftif kuantitatif yang memberikan gambaran mengenai cara pengelolaan persampahan di kota Pangkajene dan pengambilan data kuantitatif berupa timbulan, dan komposisi sampah. Menurut hasil penelitian jumlah keseluruhan sampah kota Pangkajene adalah $92,52 \mathrm{~m}^{3} / \mathrm{hari}$. Rata-rata sampah yang dihasilkan adalah $2,06 \mathrm{~m}^{3} /$ hari/orang. Dari hasil perhitungan kebutuhan infastruktur persampahan maka diperoleh 900 buah, 46 unit gerobak, 19 unit kontainer dan 4 unit truk setiap harinya. Dari hasil penelitian disimpulkan bahwa sistem pengelolaan sampah di kota Pangkajene perlu untuk ditingkatkan dari segi infrastruktur dan tingkat pelayanannya agar lebih memaksimalkan kegiatan operasional persampahan.
\end{abstract}

Kata kunci: Sampah, Garbage Generation, Komposisi Sampah, Solid Waste Infrastructure

\section{ABSTRACT}

The increase in population greatly affects the measure of waste generation. The huge measure of waste is not supported by the number of waste management facilities and infrastructure, resulting in problems in waste management, such as transportation to final disposal of waste that is not properly accommodated, causing disease, dirty environment, reducing river carrying capacity and so on. This research was conducted to determine how waste management is in the city of Pangkajene and determine the infrastructure requirements for solid waste operational activities. This research is a quantitative descriptive study that gives an outline of how to oversee strong waste in the city of Pangkajene and the collection of quantitative data in the form of generation and composition of waste. According to the results of the research, the total amount of waste from the city of Pangkajene is $92.52 \mathrm{m3} /$ day. The average waste generated is $2.06 \mathrm{~m} 3$ / day / person. From the calculation of solid waste infrastructure needs, it is obtained 900 units, 46 units of carts, 19 units of containers and 4 units of trucks every day. From the research results, it is concluded that the waste management system in Pangkajene city needs to be improved in terms of infrastructure and service levels in order to maximize solid waste operational activities.

\section{Keywords: Garbage, Garbage Generation, Garbage Composition, Solid Waste Infrastructure}

\section{PENDAHULUAN}

Pertambahan jumlah penduduk, perubahan gaya dan pola hidup manusia berpengaruh terhadap peningkatan jumlah timbulan sampah, jenis, dan keberagaman karakteristik sampah.

Sampah adalah sisa aktivitas manusia yang berbentuk padat [10]. Sampah adalah hasil dari aktifitas manusia yang tidak digunakan baik yang tidak digunakan lagi maupun yang sudah diambil bagian utama [5]. Timbulan sampah merupakan jumlah sampah yang dihasilkan pada suatu kurun waktu tertentu, pada umumnya dinyatakan dalam satuan berat atau volume [1]. Pada dasarnya sampah berasal dari daerah permukiman, perdagangan, industri, perkantoran, taman, perkebunan, dan pertanian [11]. Sampah digolongkan dalam dua jenis berdasarkan sumbernya yaitu sampah domestik dan sampah non domestic [8]. Sampah domestik merupakan sampah yang dihasilkan langsung oleh aktivitas manusia seperti pasar, sekolah dan permukiman, sedangkan sampah non-domestik yang bersumber dari aktivitas pertanian, perternakan, industri, transportasi, pabrik dan sebagainya. Berdasarkan fisiknya sampai dibagi menjadi 2 (dua) jenis yaitu sampah basah yang pada umumnya berasal dari sampah rumah tangga yang sifatnya mudah busuk dan sampah kering seperti kertas, kayu, kaleng, dan sebagainya [4]. Pembuangan sampah yang tidak diakomodir dengan baik dapat mempengaruhi kesehatan lingkungan yang berpotensi menimbulkan berbagai penyakit seperti penyakit.

Pada sistem pengelolaan sampah dibutuhkan kontribus dari masyarakat agar bisa mengelola sampah menggunakan metode 3R (Reduce, Reuse, dan Recycle) [3]. Dalam hal ini masyarakat dapat memilah sampah basah dan sampah kering [12]. 
Pengelolaan sampah merupakan tindakan untuk mengatur sampah dari proses pengumpulan sampai pembuangan akhir [2]. Pengelolaan sampah dimulai dari timbulan, hingga pembuangan sampah. Faktorfaktor yang berpengaruh dalam pengelolaan sampah seperti tingkat pendidikan, penempatan wadah sampah di rumah, pemulung, aksi kebersihan, peraturan mengenai persampahan dan tindak hukumnya [7].

\section{METODOLOGI PENELITIAN}

Lokasi penelitian di Sekolah, Kompleks Haji Rako, Ruko, kantor, Pasar, Warung Makan, Jalanan, Rumah Sakit. Penelitian dilakukan selama 8 hari pada pukul 08.30 WITA pada tanggal 9-16 Juli 2012.

Data primer yang digunakan berupa sampel sampah yang dibagi menurut sumbernya. Penentuan jumlah sampel menggunakan metode pengambilan dan pengukuran timbulan sampah [9].

Penelitian ini menggunakan metode sampling untuk mengetahui jumlah tmbulan dan komposisi sampah.
Metode sampling merupakan cara menentukan jumlah sampel yang disesuaikan dengan jumlah data sebenarnya [6]. Sampel sampah dimasukkan ke dalam box yang berukuran $30 \mathrm{~cm} \times 30 \mathrm{~cm} \times 50 \mathrm{~cm}$ tanpa dipadatkan. Sebagai standar kompaksi box sampel dijatuhkan dari ketinggian $\pm 20 \mathrm{~cm}$ sebanyak 3 kali. Kemudian mengukur tinggi sampah untuk mengetahui volume timbulan sampah dan melakukan penimbangan untuk mengetahui berat sampah.

\section{HASIL DAN PEMBAHASAN}

\section{A. Proyeksi Pertumbuhan Penduduk}

Untuk mengetahui proyeksi pertumbuhan penduduk di Kota Pangkajene digunakan pendekatan Metode Least Square, Aritmetika, dan Geometrik.

\section{Metode Least Square}

Metode ini menggunakan rumus sebagai berikut :

$\boldsymbol{Y}=\boldsymbol{a} \cdot \boldsymbol{m}+\boldsymbol{b}$

Tabel 1. Hasil perhitungan menggunakan metode Least Square

\begin{tabular}{cccccc}
\hline No. & Tahun & $\mathrm{m}$ & $\mathrm{n} \mathrm{n}^{2}$ & $\mathrm{n}$ & $\mathrm{m} . \mathrm{n}$ \\
\hline 1. & 2000 & -6 & 36 & 35.51 & -213.06 \\
2. & 2001 & -5 & 25 & 36.01 & -180.04 \\
3. & 2002 & -4 & 16 & 36.18 & -144.73 \\
4. & 2003 & -3 & 9 & 36.37 & -109.10 \\
5. & 2004 & -2 & 4 & 37.39 & -74.77 \\
6. & 2005 & -1 & 1 & 38.10 & -38.09 \\
7. & 2006 & 0 & 0 & 38.52 & 0 \\
8. & 2007 & 1 & 1 & 38.52 & 38.53 \\
9. & 2008 & 2 & 4 & 39.88 & 79.76 \\
10. & 2009 & 3 & 9 & 39.87 & 119.59 \\
11. & 2010 & 4 & 16 & 41.60 & 166.40 \\
12. & 2011 & 5 & 25 & 43.34 & 216.71 \\
13. & 2012 & 6 & 36 & 45.01 & 270.05 \\
\hline
\end{tabular}

Catatan : N: 13; diambil tahun dasar 2006

$$
\begin{array}{r}
a=\frac{N \cdot \Sigma m n-\Sigma m \cdot \Sigma n}{N \cdot \Sigma m^{2}-\left(\Sigma m^{2}\right)} \\
b=\frac{\Sigma m^{2} \cdot \Sigma n-\Sigma m \cdot \Sigma m n}{N \cdot \Sigma m^{2}-\left(m^{2}\right)} \\
a=\frac{13 \cdot 131.249-0 \cdot 506.283}{13 \cdot 164-\left(0^{2}\right)} \\
=800,3 \\
b=\frac{164 \cdot 506.283-0 \cdot 30.830}{13 \cdot 164-\left(0^{2}\right)} \\
=38.944,85
\end{array}
$$

Sehingga perkiraan jumlah penduduk pada tahun 2017 dengan Metode Least Square adalah :

$$
\begin{aligned}
P_{2017}= & a \cdot x+b \\
& =800,3.18+38.944,85 \\
& =53.350 \text { jiwa }
\end{aligned}
$$

\section{Perhitungan dengan metode Aritmetika (Arithmetical Increase Methode)}

Perhitungan proyeksi jumlah penduduk dengan metode ini dengan menggunakan rumus:

$\boldsymbol{P}_{\boldsymbol{n}}=\boldsymbol{P}_{\mathrm{o}}+\boldsymbol{n} \cdot \boldsymbol{q}$

Dimana :

$$
q=\frac{P_{\text {akhir }}-P_{\text {awal }}}{12}
$$




$$
\begin{aligned}
& =\frac{45.008-35.510}{12} \\
& =791,5
\end{aligned}
$$

Perkiraan jumlah penduduk pada tahun 2017 dengan Metode Aritmetika sebesar :

$$
\begin{aligned}
P_{2017}=P_{2012} & +5 \cdot 791,5 \\
& =48.966 \text { jiwa }
\end{aligned}
$$

\section{Perhitungan dengan metode Geometrik (Geometrical Increase Methode)}

Perhitungan proyeksi jumlah penduduk dengan metode ini dengan menggunakan rumus:

$P_{n}=P_{o} \cdot(1+r)^{n}$

Dimana :

$$
\begin{aligned}
r & =\left(P_{\text {akhir }} / P_{\text {awal }}\right)^{1 / n}-1 \\
& =(45.008 / 35.510)^{1 / 12}-1 \\
& =0.89 \%
\end{aligned}
$$

Perkiraan jumlah penduduk pada tahun 2017 dengan Metode Aritmetika sebesar :

$P_{2017}=P_{2012}(1+0.0089)^{5}$

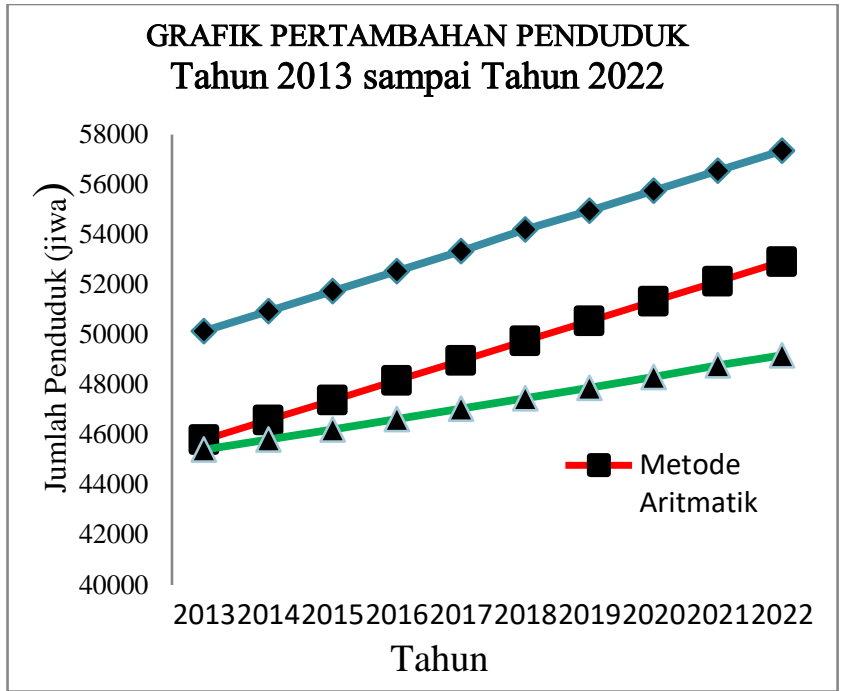

Gambar 1. Grafik Pertambahan Penduduk

Untuk menentukan metode yang tepat untuk proyeksi timbulan sampah yang dihasilkan, maka perlu analisis korelasi $(R)$ dari tiap metode dengan

\begin{tabular}{|c|c|c|c|c|c|c|}
\hline No. & Tahun & $\mathrm{m}$ & $m^{2}$ & $\mathrm{n}$ & $n^{2}$ & m.n \\
\hline 1 & 2000 & -6 & 36 & 38.945 & 1.516 .701 .342 & -233.669 \\
\hline 2 & 2001 & -5 & 25 & 39.745 & 1.579.676.949 & -198.726 \\
\hline 3 & 2002 & -4 & 16 & 40.545 & 1.643 .933 .516 & -162.182 \\
\hline 4 & 2003 & -3 & 9 & 41.346 & 1.709 .471 .043 & -124.037 \\
\hline 5 & 2004 & -2 & 4 & 42.146 & 1.776.289.531 & -84.292 \\
\hline 6 & 2005 & -1 & 1 & 42.946 & 1.844.388.978 & -42.946 \\
\hline 7 & 2006 & 0 & 0 & 43.747 & 1.913.769.386 & 0 \\
\hline 8 & 2007 & 1 & 1 & 44.547 & 1.984.430.754 & 44.547 \\
\hline 9 & 2008 & 2 & 4 & 45.347 & 2.056.373.083 & 90.695 \\
\hline 10 & 2009 & 3 & 9 & 46.148 & 2.129 .596 .371 & 138.443 \\
\hline 11 & 2010 & 4 & 16 & 46.948 & 2.204.100.620 & 187.791 \\
\hline 12 & 2011 & 5 & 25 & 47.748 & 2.279.885.828 & 238.741 \\
\hline 13 & 2012 & 6 & 36 & 48.548 & 2.356.951.997 & 291.291 \\
\hline \multicolumn{2}{|c|}{ Jumlah } & 0 & 182 & 520.158 & 24.995 .569 .397 & 145.655 \\
\hline
\end{tabular}
menggunakan rumus :

$$
R=\frac{N \cdot \Sigma m n-\Sigma m \cdot \Sigma n}{\sqrt{\left[N \cdot \Sigma n^{2}-(\Sigma n)^{2}\right]\left[N \cdot \Sigma m^{2}-(\Sigma m)^{2}\right]}}
$$

Hasil perhitungan korelasi dapat dilihat dalam tabel 2 dibawah ini :

Metode Least Square

Tabel 2. Analisa Korelasi Metode Least Square
Perhitungan koefisien korelasi ( R ) Least Square:

$R$

$$
\begin{aligned}
& =\frac{13 \cdot 145 \cdot 655-0.520 \cdot 158}{\sqrt{\left[13 \cdot(24 \cdot 995 \cdot 569 \cdot 397)-(520 \cdot 158)^{2}\right]\left[13 \cdot 182-(0)^{2}\right]}} \\
& =0,9999576769
\end{aligned}
$$

Hasil perhitungan analisa korelasi $(R)$ dari ketiga metode bisa dilihat pada tabel 3. Dari hasil perhitungan dapat diketahui koef. korelasi metode Aritmetika lebih besar daripada metode least square dan Geometrik, maka pendekatan pertumbuhan penduduk menggunakan metode Aritmetika.

Tabel 3. Hasil Perhitungan Koefisien Korelasi (R ) 


\begin{tabular}{ccc}
\hline No. & Metode & $\begin{array}{c}\text { Hasil Analisa Korelasi } \\
(\mathrm{R})\end{array}$ \\
\hline 1 & Least Square & 0,9999576769 \\
2 & Aritmetika & $\mathbf{0 . 9 9 9 9 9 9 2 3 6 5}$ \\
3 & Geometrik & 0.9999899080 \\
\hline
\end{tabular}

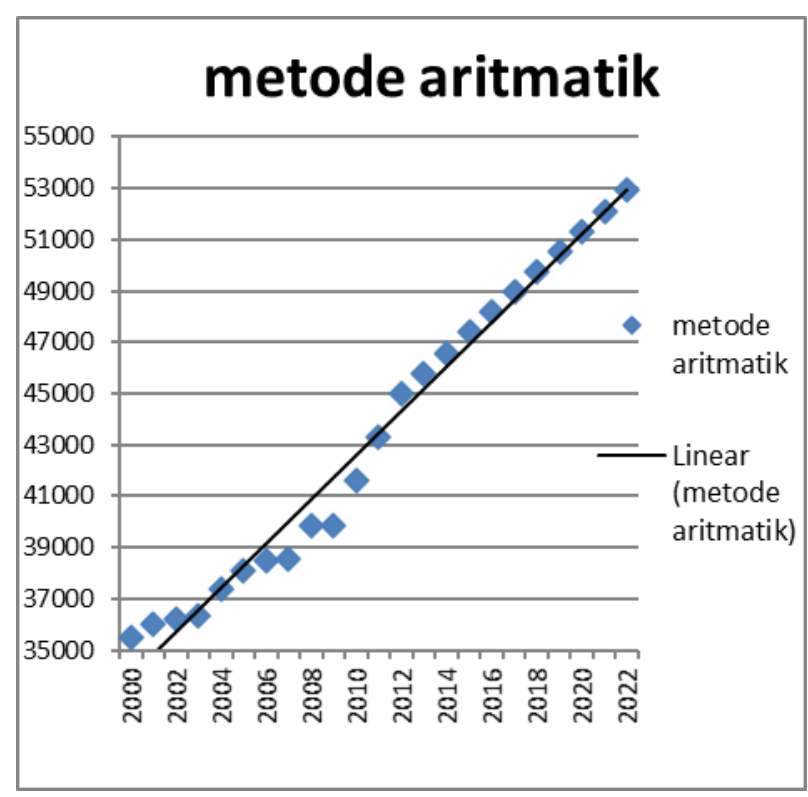

Gambar 2. Grafik Trend Linear Metode Aritmatik

\section{B. Timbulan Sampah}

Dari hasil pengukuran didapatkan jumlah timbulan sampah keseluruhan baik di area perumahan maupun non perumahan. Besrnya timbulan sampah dapat dilihat pada tabel 4 .

Tabel 4. Total Timbulan Sampah Kota Pangkajene

\begin{tabular}{llcl}
\hline No. & Nama Bangunan & Jumlah & $\begin{array}{l}\text { Timbulan } \\
\text { (liter/hari) }\end{array}$ \\
\hline 1. & Perumahan & 9.433 & 68.964 \\
2. & Non Perumahan & 49 & $2.042,96$ \\
& -Sekolah & 384 & 2.720 \\
& -Ruko & 34 & 455,24 \\
& -Kantor & 61 & 817,095 \\
& -Warung Makan & 16 & $3.363,2$ \\
& -Fasilitas Kesehatan & 320 pdgng & 8.312 \\
& -Pasar & $41,816 \mathrm{~km}$ & 5.854 \\
\hline & -Jalan & & 92. \\
\hline \multirow{2}{*}{ Jumlah } & & 516,99 \\
\hline
\end{tabular}

\section{Proyeksi Jumlah Timbulan Sampah}

Untuk merencanakan sistem pengelolaan sampah,maka harus diketahui volume timbulan sampah yang dihasilkan dalam suatu wilayah. Pertambahn besar timbulan sampah berbanding lurus dengan jumlah penduduk. Semakin besar jumlah penduduk pada suatu wilayah, maka semakin besar pula jumlah volume timbulan sampah.

$$
\frac{92.516,99}{45.008}=2,056 \text { liter/org/hari }
$$

Proyeksi timbulan sampah tahun 2022 dapat diketahui dengan rumus :

$$
\begin{aligned}
\mathrm{V}_{\mathrm{Tn}}=\Sigma \mathrm{P} \cdot \Sigma \mathrm{V}_{\mathrm{T}} \\
\mathrm{V}_{\mathrm{T} 2022}=52.923 \text { jiwa } \times 2,056 \mathrm{ltr} / \mathrm{hri} / \mathrm{org} \\
=108.809,69 \text { liter/hari }
\end{aligned}
$$

Proyeksi timbulan sampah selama sepuluh tahun dapat dilihat pada tabel 5 .

Tabel 5. Proyeksi Timbulan Sampah Perumahan di Kota Pangkajene

\begin{tabular}{cccc}
\hline No. & Tahun & $\begin{array}{c}\text { Jumlah } \\
\text { Penduduk } \\
\text { (jiwa) }\end{array}$ & $\begin{array}{c}\text { Jumlah } \\
\text { Sampah } \\
\text { (liter/hari) }\end{array}$ \\
\hline $\mathbf{1}$ & 2012 & 45.008 & $92.516,99$ \\
$\mathbf{2}$ & 2013 & 45.800 & $94.164,8$ \\
$\mathbf{3}$ & 2014 & 46.591 & $95.791,09$ \\
$\mathbf{4}$ & 2015 & 47.383 & $97.419,45$ \\
$\mathbf{5}$ & 2016 & 48.174 & $99.045,74$ \\
$\mathbf{6}$ & 2017 & 48.966 & $100.674,09$ \\
$\mathbf{7}$ & 2018 & 49.757 & $102.300,39$ \\
$\mathbf{8}$ & 2019 & 50.549 & $103.928,74$ \\
$\mathbf{9}$ & 2020 & 51.340 & $105.555,04$ \\
$\mathbf{1 0}$ & 2021 & 52.132 & $107.183,39$ \\
\hline
\end{tabular}

\section{Analisa Komposisi Sampah}

Menurut jenisnya sampah dibagi dua jenis yaitu sampah organik dan sampah anorganik. Dari hasil penelitian komposisi jenis sampah yang dihasilkan setiap hari dapat diketahui persentase sampah organik sebesar $55,76 \%$ dan sampah anorganik sebesar $42,24 \%$ yang terdiri dari kertas, kain, kayu, plastik, logam, kaca dan karet/kulit.

\section{E. Infrastruktur Persampahan}

Berdasarkan hasil perhitungan untuk jumlah kebutuhan infastruktur persampahan diperoleh 900 buah untuk perwadahan, 46 unit gerobak, 19 unit container dan 4(empat) unit truk. Hasil perhitungan ini jika dibandingkan dengan jumlah infrastruktur yang ada jumlahnya masih sedikit, maka perlu adanya penambahan infrastruktur agar membantu kelancaran kegiatan operasional persampahan.

\section{KESIMPULAN DAN SARAN}

\section{A.Kesimpulan}

Jumlah timbunan sampah yang ada di Kota Pangkajene pada tahun 2012 adalah $92,517 \mathrm{~m}^{3} /$ hari dengan jumlah penduduk mencapai 45.008 jiwa. Sedangkan pada tahun 2022 jumlah timbulan sampah sebesar $108.809 \mathrm{~m}^{3} /$ hari dengan jumlah penduduk sebanyak 52.923 jiwa. 
Kebutuhan peralatan pada tahun 2012 untuk container sebanyak 19 unit dan truk 4 unit sedangkan kebutuhan gerobak sebanyak 46 unit. Untuk pewadahan dibutuhkan 900 buah dengan kapasitas 10 liter. Sedangkan untuk tahun 2022 mendatang dibutuhkan untuk sebanyak 22 unit kontainer, 5 unit truk dan sebanyak 1.059 buah perwadahan dengan kapasitas 10 liter.

\section{B.Saran}

Peningkatan sumber daya manusia yang ada pada dinas kebersihan kota Pangkajene baik sebagai aparat maupun pelaksana operasional dilapangan.

Pentingnya kesadaran masyarakat akan pengolahan persampahan dan kontribusi masyarakat untuk ikut mendukung pelaksanaan operasional persampahan baik secara materi maupun secara moral.

Kegiatan operasional persampahan perlu dimaksimalkan dari segi pelayanan seperti manajemen pengolahan yang terstruktur dengan menambah jumlah rit dan waktu operasional.

\section{DAFTAR PUSTAKA}

[1] Damanhuri, E. 2010. Diktat Pengelolaan Sampah. Teknik Lingkungan Institut Teknologi Bandung (ITB): Bandung.

[2] Dinas Cipta Karya, 1993. Penyusunan Pedoman Teknik Operasi dan Pemeliharaan Pembangunan Prasarana Perkotaan (Komponen Persampahan). Jakarta.

[3] Dinas Pekerjaan Umum. 2007. Pedoman Umum 3R Berbasis Masyarakat di Kawasan Pemukiman. Jakarta (ID): Direktorat Pengembangan Penyehatan Lingkungan Pemukiman.

[4] Gilbert, M.,dkk., Konsep Pendidikan Lingkungan Hidup dan "Wall Chart". Buku Panduan Pendidikan Lingkungan Hidup, Malang: PPPGT/VEDC, 1996.
[5] Hadi, W, 1998, Teknologi Pengelolaan Sampah kota Besar Berbagai studiKasus di Indonesia, Seminar Nasional Penanganan Sampah Kota, Fakultas Teknik Sipil dan Perencanaan Institut Teknologi Surabaya, Surabaya

[6] Margono, 2004, Metodologi Penelitian Pendidikan, Jakarta :Rineka Cipta.

[7] Nitikesari, Putu Ening. 2005. Analisis Tingkat Partisipasi Masyarakat dalam Penanganan Sampah Secara Mandiri di Kota Denpasar. Tesis Magister Program Pascasarjana Universitas Udayana, Denpasar.

[8] Prihandarini. 2004. Manajemen Sampah Daur Ulang Sampah Menjadi Pupuk Organik. Jakarta: perpod.

[9] Standar Nasional Indonesia Nomor SNI-19-39641994 Tentang Metode Pengambilan dan Pengukuran Contoh Timbulan dan Komposisi Sampah Perkotaan, Badan Standar Nasional (BSN ).

[10] Undang-Undang No. 18 Tahun 2008 tentang Pengelolaan Sampah

[11] Tchobanoglous, G. Theisen, H. dan Vigil, S.1993. Integrated Solid Waste Management: Engineering Principles and Management Issues. Mc.Graw-Hill, Inc. Singapore

[12] Yolarita E. 2011. Pengelolaan sampah dengan prinsip 3R di Kota Solok. Tesis. Universitas Pajajaran Bandung.Tersedia pada: http://pustaka.unpad.ac.id/archives/119693. 